\title{
O OUTRO TAMBÉM PODE TER RAZÃO - PARA ALÉM DE ELE TER APENAS SEUS DIREITOS RECONHECIDOS*
}

\author{
Luiz Rohden** \\ http://orcid.org/0000-0001-6143-090X \\ rohden@unisinos.br
}

RESUMO Este artigo constitui um desdobramento da reflexão sobre a Hermenêutica enquanto ética tecida em torno da cunhagem, da descrição e da fundamentação da expressão Eu Hermeneuticus, que trata o outro como fim em si mesmo e não como um objeto. Aqui, sob a égide do pressuposto gadameriano segundo o qual "o outro não somente tem também um direito, mas talvez também pode ter razão”, pretendo evidenciar e justificar a centralidade da alteridade na teoria e na práxis da hermenêutica filosófica. A compreensão filosófica erige-se sobre o exercício de reconhecimento dos direitos aos direitos do outro, mas também sobre as razões dos seus argumentos, exercício que gera implicações éticas importantes em termos pessoais e sociais, como mostrarei. Com isso, viso mostrar e fundamentar a face e a função ética da hermenêutica filosófica com escopo de sedimentar o projeto de uma Hermenêutica Ética.

Palavras-chave Hermenêutica, Gadamer, Ética, Alteridade, Direito.

ABSTRACT This article is a second movement of the reflection on Hermeneutics as ethics woven around the coinage, description and foundation of the expression I Hermeneuticus that treats the other as an end in itself and not as an object. Here, under the aegis of the Gadamerian assumption that "the other

* Artigo submetido em 26/09/19. Aceito em 10/03/20.

** Universidade Do Vale Do Rio Dos Sinos. São Leopoldo, RS, Brasil. Este artigo contou com apoio da FAPERGS - PQg 2017 e do CNPq - Edital Universal 2018. 
not only has a right, but may also be right", I intend to highlight and justify the centrality of otherness in the theory and praxis of philosophical hermeneutics. Philosophical understanding arises from the exercise of recognition of the rights of the other, but also of the reasons for their arguments, an exercise that generates important personal and social ethical implications as I will show. With this, I intend to show and substantiate the ethical face and function of philosophical hermeneutics hoping to consolidate the project of an Ethical Hermeneutics.

Keywords Hermeneutics, Gadamer, Ethics, Alterity, Law.

o que eu quero dizer tem a ver com a pressuposição de que talvez o outro não somente tem também um direito, mas talvez também pode ter razão (Gadamer, 1993a, p. 109). ${ }^{1}$

\section{Estado da questão ou sobre a centralidade da alteridade na hermenêutica filosófica}

Ao nos debruçarmos sobre hermenêutica não nos é difícil perceber algo que lhe é basilar e próprio, a saber, a temática do outro. Já em sua gênese mitológica, isso se estampa no modo de atuar de Hermes, que, continuamente, transpõe e traduz mensagens entre este e o outro mundo e vice-versa, institui pontes entre o reino dos vivos e dos mortos, dos humanos e dos deuses. A hermenêutica existe porque pressupõe a existência do outro e se dispõe a lidar com o não dito, a diferença, a negatividade e vigora onde há necessidade de instaurar a terceira margem.

Conhecemos a centralidade do tema alteridade na filosofia de Emanuel Lévinas, o que não nos permite concluir que ele seja objeto exclusivo de seu projeto. Embora encontremos vínculos estreitos entre a abordagem de Lévinas e a de Gadamer com relação ao papel da alteridade, vou-me ater, aqui, à investigação do tema na hermenêutica gadameriana.

Meu interesse precípuo em explicitar e apontar o lugar de destaque do outro na estrutura e na práxis da hermenêutica filosófica estriba-se em duas razões: em primeiro lugar, ela permite evidenciar e justificar sua dimensão ética. Isso me permitirá fundamentar o projeto de uma hermenêutica ética. 
Trata-se de uma proposta teórica original e pertinente à medida que Gadamer mencionou, em diversos escritos, a centralidade do outro, mas não se dedicou ao seu desenvolvimento. Da minha parte, além de rastrear, explicitar e aprofundar alcance dessa temática, proponho desdobrar a pertinência da pressuposição hermenêutica segundo a qual o outro não possui somente direitos, mas pode ainda ter razão - o que Gadamer apenas mencionou, mas não aprofundou - e que elegi como objeto de reflexão com o escopo, inovador, de justificar e fundamentar a feição ética da Hermenêutica. Além disso, sob a égide da hermenêutica gadameriana, outro aspecto original dessa reflexão consiste em argumentar em torno da necessidade premente de levarmos a sério e aprendermos a lidar com os direitos e as razões do outro com o fito de instituir um ethos habitável, minimamente harmônico, em contraposição às crescentes ondas de intolerância de toda ordem, marcadas pelo dogmatismo, pelo totalitarismo como desenvolverei na conclusão desse texto.

A centralidade do outro na hermenêutica filosófica é patente em Gadamer e pode ser aferida pela citação de Schleiermacher - que é epígrafe da III Parte de Verdade e Método I - a saber, de "que a arte da compreensão não é necessária somente para o trato com os textos, mas também no trato com pessoas" (Gadamer, 1993b, p. 300). Ratificam a centralidade do outro as seguintes afirmações do próprio Gadamer que são basilares da teoria e da prática hermenêutica: "o que eu quero dizer tem a ver com a pressuposição de que talvez o outro não somente tem também um direito, mas talvez também pode ter razão" (Gadamer, 1993a, p. 109) e "a possibilidade de que o outro tenha razão é a alma da hermenêutica" (Gadamer in Grondin, 1991, p. 160). Além disso, essa hipótese é ratificada pela leitura que seus discípulos e intérpretes fizeram ao rastrearem o papel central do outro na hermenêutica. Dennis Schmidt (2012, p. 36) sustenta que "a hermenêutica [...] anima-se por um profundo respeito pela alteridade”. Para James Risser (1997, p. 15),

\footnotetext{
a ênfase no outro sempre esteve presente nos escritos de Gadamer. Novamente, ao recontar seu próprio itinerário filosófico, Gadamer nos diz que uma das motivações para sua hermenêutica filosófica foi a crise do idealismo que, durante sua juventude, originou-se com a crítica kierkegaardiana de Hegel. Nessa crítica, o significado da compreensão toma sua orientação do outro que invade meu egocentrismo e me dá algo para entender.
}

Em segundo lugar, a pertinência filosófica dessa investigação justifica-se à medida que crescem as manifestações e as posturas dogmáticas, totalitárias, nos diferentes níveis da realidade humana, calcadas, em última análise, sobre a intenção de excluir ou eliminar o outro. À base das diferentes formas de 
fundamentalismos e fanatismos de matiz religioso, de totalitarismos de ordem sociopolítica, de dogmatismos conceituais, detectamos uma forma de pensar e de proceder que visa até exterminar o outro. Ao explorar o sentido da possibilidade de que o outro não apenas possui direitos, mas também pode ainda ter razão, prestamos uma contribuição sociopolítica porque, além de evidenciarmos a centralidade do outro, sugerimos a necessidade de superar propostas teóricas racistas, homofóbicas, xenofóbicas. Ao trazer à luz a centralidade do outro na hermenêutica gadameriana, justifico sua vocação ética.

À esteira de Gadamer, pretendo mostrar que a face ética da hermenêutica pela reflexão sobre a centralidade do outro articulada sobre dois pilares: a. $O$ outro pode não apenas ter direito; b. o outro pode, talvez, também ter razão. $\mathrm{O}$ exercício teórico e prático, de saber lidar com os direitos e as razões do outro, produz implicações éticas de ordem pessoal - isto é, em quem procura pensar e agir dessa forma - social e ecológica, imprescindíveis para evitarmos o caos do nosso ethos, bem como cessarmos ou minimizarmos a destruição do nosso planeta. Com o desenvolvimento dessa dimensão, assinalo para o que pode ser chamado do projeto de uma hermenêutica do cuidado do outro em complemento à hermenêutica enquanto cuidado de si, conforme já desenvolvido em outro artigo meu.

\section{Sobre o outro enquanto pressuposto da hermenêutica}

A possibilidade de que o outro tenha razão, é a alma da hermenêutica (Gadamer, in Grondin, 1991, p. 160).

$\mathrm{Na}$ reflexão que se segue, explicitarei traços da identidade do outro hermenêutico enquanto sujeito de direitos e de razões ou de argumentos. Se, por um lado, ele não deve ser visto como refém de um eu, por outro lado, o outro não o destrona dos seus direitos nem das suas razões. Com essa reflexão sobre o outro hermeneuticus, complemento - sem esgotar - o arco teórico da hermenêutica enquanto ética a partir do processo relacional entre o eu hermeneuticus ${ }^{2}$ e o outro ou o tu hermeneuticus assentado sobre o pressuposto posturas éticas por parte daquele que compreende. Lembro que, para tanto, cunhei e fundamentei a noção de Eu Hermeneuticus no artigo "Sobre o Eu hermeneuticus, pressuposto da Hermenêutica ética". Assim como podemos falar de um Eu cartesiano ou Eu humiano, justifico a existência de um Eu Hermeneuticus a partir da relação triádica Eu-Tu desenvolvida por Gadamer, em Verdade e Método I. São posturas próprias, éticas, desse Eu Hermeneuticus: abrir-se ao outro; tratar o outro como outro; deixar o outro lhe dizer algo, ouvir o outro, deixar-se tocar e afetar pelo outro, deixar valer alguma coisa contraposta ao eu, atitude de humildade. 
ou imperativo de abertura mútua que não é exigida "só por parte de quem fala; mas preferencialmente, quem é capaz de acolher a palavra do outro, é fundamentalmente aberto. Se não existe esta mútua abertura, tampouco existe verdadeiro vínculo humano" (Gadamer, 1999, p. 367). A instauração de um ethos que fomente a liberdade, a criatividade, a responsabilidade depende, em grande parte, da práxis da abertura do eu hermeneuticus e do outro hermeneuticus comprometidos com o exercício de ouvir, de respeitar, de acolher, de deixar-se afetar pela palavra do outro e, enfim, de ser constituído e transformado pela relação com outro. É isso que torna possível e efetiva a criação de vínculos humanos autênticos, genuínos, que nos impulsionem a cuidar de nós mesmos e dos outros (Cf. Rohden, 2004).

\subsection{Sobre o "outro tem um direito"}

$\mathrm{Na}$ afirmação "talvez, o outro não somente tem também um direito", nos deparamos com o aspecto segundo o qual o outro é sujeito de direitos antes que um eu os reconheça ou tenha a pretensão de lhe outorgar ou retirar (seus direitos). O direito do outro é, pois, ontológico, isto é, precede à decisão arbitrária de um eu pretender querer ou conceder (um direito ao outro). Em outros termos, no exercício de compreensão filosófico está embutido o pressuposto segundo o qual, o direito aos direitos do outro (dignidade, vida, saúde, educação, liberdade) lhe pertence, lhe é, por assim, dizer, natural - nos moldes da argumentação da Antígona. Nesse sentido, o outro não tem direito aos seus direitos porque alguém lhe concede, mas antes esse alguém precisa apenas a aprender a reconhecê-lo como algo que lhe é próprio. O reconhecimento do direito do outro que representa a dimensão sociopolítica é assegurado pela lei positiva. Na Antígona, Creonte representa, de certo modo, essa face objetiva, legal, escrita do direito do eu aos seus direitos.

Podemos dizer que o reconhecimento do direito do outro aos seus direitos se encontra representado e assegurado na face metodológica estampada no título da obra Verdade e Método. A práxis hermenêutica, pautada pelo princípio

\footnotetext{
O eu hermeneuticus se dispõe a jogar com os outros e não apenas contra os outros, exercita seu ouvido à voz do outro, é capaz de sair de sua Ítaca ciente de que voltará diferente, se habilita a conhecer, reconhecer e conceder não apenas o direito, mas, também razão ao outro, enfim, pratica o respeito ao outro ao ponto de ainda se solidarizar com ele. Em termos metafísicos, o eu hermeneuticus rompe a lógica binária do conhecer enquanto mera adequação entre a coisa e o intelecto e institui a apropriação e a conceitualização do real tecido pela finitude segundo a lógica do terceiro incluído. O eu hermeneuticus é, pois, um pressuposto fundamental para a iniciação ao pensar de "forma oikoumênica" o que é um imperativo para a humanidade "que tem que fazê-lo para aprender a conviver e talvez poder adiar assim a autodestruição ou evitá-la". Não basta não dever tratar o outro como instrumento, mas é imprescindível tratar o outro como gostaríamos de ser tratados, instituindo um ethos em que reina liberdade que possibilita a criação de redes entre as pessoas e entre estas e a natureza.
} 
segundo o qual o outro não pode ser tratado como meio, mas como fim, pressupõe a articulação entre a instauração do sentido e da verdade em diálogo com o método científico. Assim, o direito aos direitos do outro se encontra assegurado pela hermenêutica filosófica, eximindo-a da pecha de propugnar o relativismo, o subjetivismo, a vacuidade argumentativa.

Faz parte da teoria e da prática hermenêutica compreender e aprimorar a arte de assegurar o direito aos direitos dos outros corporificados na forma de lei. Pertence também à sua práxis instituir caminhos para reivindicá-los e assegurá-los. Esse esforço especulativo faz parte das atividades do grupo de pesquisa liderado pelo prof. Lenio Streck (2013, 2017), alocado no Programa de Pós-Graduação do Direito da Unisinos.

Reconhecer o direito do outro aos seus direitos constitui o primeiro degrau da postura ética passível de ser extraída e instituída na formulação "talvez o outro não somente tem também um direito". Complementa esse degrau da hermenêutica, enquanto uma práxis ética, a postura do eu relativo ao outro facultada pela possibilidade de que o outro possa não apenas ter direito aos seus direitos reconhecidos e assegurados, mas ele pode, também, talvez, ter razão.

2.2. Sobre "o outro pode, também, talvez, ter razão"

os deuses, pai, implantam no homem a razão - o bem maior de todos. Se falaste certo acerca dessas coisas, não posso dizer (jamais em minha vida eu seja capaz disso!). Mas os outros também podem ter boas ideias (Sófocles, 1990, p. 225).

Partindo do pressuposto segundo o qual o exercício filosófico erige-se sobre a arte de dar e de acolher argumentos com vistas à instituição de uma teoria ou de um conceito, pertence à espinha dorsal da hermenêutica articular o princípio de que o outro é sujeito de direitos e pode, ainda, talvez, ter razão, ou seja, seus argumentos podem ser mais apropriados aos casos em questão.

2.2.1. A possibilidade de que o outro possa ter razão é pressuposto para elaborar uma linguagem universal

Um aspecto próprio da hermenêutica consiste em compreender e justificar, universalmente, sua interpretação tecida com o acolhimento, a concessão e o reconhecimento das razões do outro. Esse modo de proceder filosófico, na esteira de Aristóteles, encontra-se sustentado pela concepção de homem enquanto "ser dotado de linguagem, e a linguagem só acontece no diálogo" (Gadamer, 1992, p. 203). O ser humano, enquanto um animal linguístico, se realiza plenamente mediante a elaboração, a troca e a fusão de argumentos com 
o outro sob a égide de que ele também pode, talvez, ter razão; porém, mesmo que suas razões possam ser equivocadas, o importante é que, ao menos, o eu procure apreender as razões das razões.

$\mathrm{Na}$ trilha do estagirita, estou de acordo de que a plenitude e a felicidade humana passa por esse árduo caminho de aprender a conhecer, reconhecer e ainda ser capaz de conceder razão às razões do outro - até mesmo e, por isso talvez, melhor ainda, às razões de um inimigo ou de um simples oponente. Platão ilustrou essa construção argumentativa no diálogo O Sofista, no qual o estrangeiro representa a instituição da possibilidade de que o outro, o não eleata, também pode ter razão! Já antes disso, na tragédia de Sófocles, aprendemos que Creonte teria evitado sua autodestruição e a violência engendrada em Tebas, se tivesse dado ouvidos à admoestação do seu filho, Hemon, a fim de instituir um ethos harmônico: "os deuses, pai, implantam no homem a razão - o bem maior de todos. Se falaste certo acerca dessas coisas, não posso dizer - jamais em minha vida eu seja capaz disso! Mas os outros também podem ter boas ideias" (Sófocles, 1990, p. 225). Pela tradução de Donaldo Schuler dessa última frase podemos apreender melhor o sentido e a força da admoestação de Hemon ao seu pai: "contudo, também a outros poderia ocorrer algo acertado" (Sófocles, 2017, p. 50).

A procura e o esforço pela instituição de uma linguagem comum aumenta a força da argumentação ao passar pela recepção e confronto com a razão ou com a palavra do outro. Em Gadamer (1992, p. 205), isso constitui uma espécie de princípio, a saber, "a palavra só encontra confirmação na recepção e aprovação pelo outro e que as conclusões que não acompanhadas do pensamento do outro perdem vigor argumentativo". Ao compreendermos procuramos, em última instância, instituir uma linguagem comum,

queremos ser compreendidos pelo outro, obter sua aprovação ou, pelo menos, uma concordância nele ou ao menos uma inserção no que foi dito, mesmo que se trata de nos contradizer ou de apresentar uma resistência, ainda quando fosse a modo de réplica ou oposição (Gadamer, 2001, p. 217).

A efetivação desse pressuposto hermenêutico acontece mediante os modelos estruturais do jogo, do círculo virtuoso e do diálogo hermenêutico (Cf. Rohden, 2003). A possibilidade de conceder razão ao outro é um pressuposto fundamental para podermos elaborar uma linguagem universal à medida que rompe com a instituição conceitual pautada exclusivamente por interesses pessoais. $\mathrm{O}$ diálogo é lugar apropriado para instituição de uma linguagem universal porque se estriba no exercício de apreender e saber lidar com as razões do outro. De acordo com Gadamer (1992, p. 204), a elaboração do conceito filosófico 
realiza-se plenamente no diálogo onde o eu se abre ao outro e o outro se abre ao eu de modo que "os fios do diálogo possam ir e vir de um ao outro", que se faz "presente só espontaneidade viva da pergunta e da resposta, do dizer e do deixar-se dizer". Porém, a busca pela linguagem universal não implica, necessariamente, a obtenção de acordos definitivos como já nos mostrou Platão com seus diálogos aporéticos.

O pressuposto é que o outro "não precisa ser compreendido como um objeto do meu desejo e eu, não como desejo momentâneo 'dele"' (Smith, 1988, p. 82). Pressupõe-se uma relação pautada pela argumentação mediante o exercício dialógico que possibilita tecer uma compreensão mais universal e apropriada à realidade. A coisa mesma, em cada questão, só pode aparecer de forma mais plena se a palavra do outro for considerada e levada a sério. Aplicado à tradição, de acordo com James Risser (1997, p. 15), "o elemento dialógico da compreensão hermenêutica significa que o que é trazido novamente à linguagem é a voz do outro" para além uma visão ou voz acerca do real. O êxito do diálogo passa pela abertura do eu e do outro o que propicia a possibilidade de que ambos, ao final, possam ter razão, uma vez que "falar é falar-conjuntamente, é a forma de elaborar conceitos e orientar-nos no mundo" (Gadamer, 2001, pp. 232-233). Enfim, "no diálogo hermenêutico, a instauração do sentido exige necessariamente que alguém seja exposto à resposta do outro. É pensar com o outro e voltar a si mesmo como se fosse em relação a um outro" (Risser, 1997, p. 16). O exercício do diálogo pressupõe e institui o cultivo do ethos da abertura, do acolhimento, da relação respeitosa que instaura o tipo mais profundo de experiência hermenêutica. De acordo com Kögler (2014, p. 15), a prática da ética do diálogo

designa um ethos da abertura como um dos fundamentos sobre os quais relações unicamente respeitosas e verdadeiramente entrelaçadas podem florescer [...] esse ethos dialógico envolve que alguém esteja disposto a ser desafiado, aberto à visão e crítica do outro. Envolve que um trabalha com o outro em um espírito para além da insistência dogmática em seu próprio direito ou de um deixar o outro ser afastando-se do diálogo.

Levar a sério as razões do outro significa, entre outras coisas, assumir a finitude da nossa compreensão e saber lidar com a liberdade das nossas ações. A instauração de uma linguagem comum, mediante a compreensão racional, nos possibilitará instituir um ethos no qual impera o respeito ao direito e ao argumento do outro. Ou seja,

sem levar a falar os conceitos, sem uma linguagem comum, não podemos encontrar palavras que toquem o outro. O caminho vai da palavra ao conceito - mas precisamos chegar do conceito à palavra, se quisermos alcançar o outro. Só assim atingimos uma compreensão racional, de uns para com os outros (Gadamer, 2000, p. 26). 
2.2.2. A possibilidade de que o outro possa ter razão pressupõe e estimula o exercício judicativo constante.

Levar em conta e trabalhar com a possibilidade de que o outro possa ter razão, além de ser imprescindível para a elaboração de conceitos filosóficos, é vital para a criação e o cultivo de vínculos humanos livres, saudáveis, responsáveis que nos possibilitam instituir um ethos no qual nos sentimos em casa no mundo. É vital porque pressupõe e implica um exercício judicativo, ou seja, lidar com a possibilidade de aceder ou não à razão do outro exige que se emita juízos constantes sobre o dito do outro. Levar em conta, analisar e ainda ser capaz de concordar com o argumento do outro significa exercitar nossa faculdade de julgar. Faz parte do compreender e, portanto, do processo de construção conceitual e do cultivo do ethos, o exercício judicativo graças ao confronto com o outro.

O diálogo filosófico pressupõe e aprimora nossa prática judicativa nas palavras de Gadamer (2001, pp. 232-233): "todos praticamos com o outro e no outro nosso juízo. Kant tem razão quando diz que o juízo não se pode aprender, mas sim apenas exercitar. Todos temos que exercitá-lo em nós". O exercício de lidar com a possibilidade de que o outro possa ter razão pressupõe e implica a prática judicativa sobre o que o outro diz, o que impede a adesão ingênua à sua palavra. Esse exercício judicativo não é cego nem sem direção, mas efetiva-se sob a égide do imperativo de jamais tratar o outro como meio, mas sempre como fim.

Uma das tarefas da hermenêutica, enquanto filosofia, consiste em denunciar a aplicação do modelo de conhecimento matemático e de regras universais à vida humana sem análise e julgamento dos casos em questão. $\mathrm{O}$ fato é que, diante do domínio da ciência empírica moderna, em termos teóricos e práticos, passamos a minimizar a importância da prática judicativa. Em outros termos, nas palavras de Gadamer (2001, p. 231), "a phronesis perdeu sua legitimidade", ou seja, passamos a ignorar "esse tipo diverso de conhecimento", que "é a faculdade de julgar" que nos permite discernir o melhor, o mais apropriado, o mais justo em cada situação, diante das razões do outro. Para Gadamer (2001, p. 232),

se olharmos para nosso sistema de ensino [...] as pessoas aprendem como se faz algo e como se tem de fazê-lo e tudo aparece bem rápido como se se pudesse fazer tudo. Em verdade, é um problema preocupante saber como, em uma sociedade cujo sistema de comunicação se aperfeiçoa cada vez mais em linguagens simbólicas artificiais, é possível fomentar e cultivar a faculdade de julgar.

Ora, a arte de julgar é tecida no exercício de levar em conta e ponderar os argumentos e as razões do outro. $\mathrm{Na}$ aprendizagem da fala "não se aprende 
certamente apenas as palavras, mas se aprende a empregá-las, a saber, como as usamos e como as compreendemos. Falar é falar um com o outro - e, com isso, trabalhamos na formação conceitual e na orientação de mundo" (Gadamer, 2001, pp. 232-233). Vejamos algumas implicações do exercício teórico e prático decorrentes do modo de lidar com outro à luz do pressuposto segundo o qual ele é portador de direitos e pode, ainda, ter razão em sua argumentação.

2.2.3. A possibilidade de que o outro possa ter razão pressupõe e estimula o exercício da responsabilidade

Levar a sério e integrar, na teoria e na prática, os direitos, mas também os argumentos dos outros, pressupõe um exercício de responsabilidade constante com o dito do outro. No âmbito hermenêutico, considere-se o dito, não apenas a fala, mas o escrito ou a simples presença na forma de uma obra de arte, por exemplo. A compreensão filosófica integra, em seu discurso e prática, a possibilidade de que o outro possa ter razão de forma responsável. Aquele que compreende - que denominamos de eu hermeneuticus, com posturas éticas próprias - não pode interpretar o outro, seja um texto, seja um fato, seja uma obra de arte ou uma pessoa, ao sabor dos seus gostos e interesses pessoais, irresponsavelmente. Embora haja sempre uma dose, necessária, de subjetividade no processo de compreensão, este não pode ser arbitrário nem reificador. A compreensão pressupõe o exercício do filósofo se comprometer e responder à palavra do outro, tratando-o como fim e não como meio. Tratálo como fim, ou seja, levar a sério seus argumentos, não significa assentir ou ratificar, tout court, o que diz, mas pensar e ponderar sobre sua fala. A prática hermenêutica não se pauta pela postura da pretensa neutralidade do intérprete diante do dito outro, mas pressupõe o esforço de responder às suas questões em seus contextos, demandando, desse modo, o "cultivo de nossa habilidade para nos envolvermos responsavelmente" (George, 2014, p. 112). De acordo com Theodor George (2014, p. 114), a compreensão filosófica visa, em última instância, à construção teórica, conceitual que "pode ser feita para responder à vida fática aumentando e refinando nossa consciência e, portanto, nosso envolvimento com nossas circunstâncias".

Para Schmidt (2012, p. 42), considerando, pois, a compreensão como "um ato contínuo que se renova a cada instante; é um modo de vida que é informado pela história, linguagem, hábitos - todas as realidades da situação da vida fática", a atividade filosófica pressupõe o exercício de responsabilidade contínua em face do outro. De acordo com Theodore George (2014, p. 119), para Gadamer, 
[...] nossa humanidade, nossa aptidão para dialogar, circula precisamente no duplo vínculo da situação: obrigada, sem exceção, pela responsabilidade que caracteriza a existência humana e, ao mesmo tempo, sempre lançada em circunstâncias que permanecem excepcionais para além de qualquer coisa podemos a priori estar preparados para compreender ou controlar (George, 2014, p. 119).

\section{Implicações éticas da prática de levar a sério o direito e as razões do outro}

\subsection{Ampliação, autorrealização, orientação pessoal}

A prática filosófica, tecida pelo exercício dialógico de compreender o outro levando a sério seus direitos e suas razões, implica a ampliação da consciência, da subjetividade. Isso porque, de acordo com Gadamer (1992, p. 206), “o diálogo com o outro, suas objeções ou sua aprovação, sua compreensão e também seus mal-entendidos são uma espécie de ampliação de nossa individualidade e uma pedra de toque do possível acordo ao qual a razão nos convida". O esforço de construir conceitos tecido sob a égide dos direitos e das razões do outro faculta ao agente alargar seus horizontes e, consequentemente, aumentam-se as probabilidades de agir de forma mais apropriada e justa às situações em que se encontra.

Em termos terapêuticos, por exemplo, o exercício de apreender os argumentos do outro e permitir que eles reverberem sobre o eu, aumenta as chances de sua cura o que lhe faculta agir de forma mais livre e responsável. A cura de limitações psicológicas, a revisão de preconceitos e a deturpações sobre o real, passa, diretamente ou indiretamente, pelo confronto com os direitos e os argumentos do outro. No caso do diálogo terapêutico,

a incapacidade para o diálogo é justamente a situação inicial a partir do qual a recuperação do diálogo se apresenta como o processo mesmo de cura [...]. O enfermo se encontra tão fixo dessas ideias que não sabe ouvir a linguagem dos outros, enquanto alimentar suas próprias ideias patológicas (Gadamer, 1992, p. 208).

Nesse caso, no ponto de partida, encontramos um eu que ignora ou despreza ou exclui o outro e seus argumentos. Essa fuga do confronto com o outro, causado pelo temor de ouvir e de tentar lidar com o argumento do outro, emperra o cuidado de mesmo e, portanto, o cuidado do outro. E são esses cuidados que possibilitam a instauração de um ethos harmônico, de cooperação mútua. A hermenêutica filosófica carrega essa pretensão, na medida em que compreender (Verstehen) consiste justamente em "pensar e ponderar sobre o que outro pensa. 
Ele poderia ter razão com o que diz e com o que propriamente quer dizer. Compreender não é, portanto, uma dominação do que nos está à frente, do outro e, em geral, do mundo objetivo" (Gadamer, 2000, p. 23).

Junto da ampliação da subjetividade, Gadamer (1999, p. 145) afirma que o exercício teórico e prático do reconhecimento do direito e das razões do outro implica, pois, um crescimento do ser (Zuwachs an Sein), ou seja, nos tornamos mais nós mesmos, melhores, mais justos, mais livres. Na prática da hermenêutica filosófica, o que importa

não é a transmissão do sentido como tal, mas a abertura infinita da comunicação na qual nos continuamos ganhamos acesso ao mundo no qual vivemos. No final, a hermenêutica filosófica trata da nossa autocompreensão; mas isso, como Gadamer insiste, tem pouco a ver com uma filosofia da subjetividade. Ao contrário, isso tem a ver com nosso modo de ser e sentir-se em casa no mundo em que somos despertados pela voz do outro (Risser, 1997, pp. 16-17).

Ao se esforçar para se por no lugar do outro, a fim de compreender seus direitos, suas razões, o eu sai de si e, ao retornar a si novamente, volta diferente, com horizonte maior - se torna mais ser, mais pleno, mais realizado. Seja num diálogo, como afirma Risser (1997, p. 16), seja numa leitura, o eu não sai ileso desses encontros, de modo que, ao final, amplifica sua visão de mundo e alarga seu modo de ser. Isso pode ser verificado exemplarmente no encontro com as obras de artes, que, como um diálogo, ao final, "sempre deixa marcas em nós. O que faz com que algo seja um diálogo não é só o fato de havermos ensinado algo novo, mas que tenhamos encontrado algo no outro que não havíamos encontrado ainda em nossa experiência de mundo" (Gadamer, 1992, p. 206). Marcas ou experiências que acabam por balizar nossas ações e procedimentos. Nossa realização ou felicidade plena se estriba no exercício de saber lidar com as razões e com os argumentos dos outros a fim de instituir um ethos harmônico no qual reina a cooperação mútua. Sabemos que pessoas felizes e realizadas são aquelas capazes de entrarem no circuito do mundo dos outros e que ainda se dispõem a aprenderem com os outros, ao passo é próprio das infelizes viverem encapsuladas no seu egoísmo, incapazes e indispostas de se abrirem aos horizontes dos outros. Dito de outra forma, nossa felicidade ou a plenitude do nosso modo de ser, se efetiva ao aprimorarmos a arte de ouvir os direitos e as razões do outro (George, 2014, p. 103).

O exercício de aprender a lidar com os direitos e as razões do outro, teórica e praticamente, pode implicar também uma possível mudança de visão de mundo e de postura. Isso porque esse exercício implica uma constante autorrevisão das concepções e das ações, o que contribui para orientar o compreender, o pensar e o agir de forma mais livres. Nas palavras de Dennis Schmidt (2012, p. 46), 
"quando tomo um texto em minhas mãos, quando entro em uma conversa ou me ligo aos idiomas da vida e outros em qualquer coisa que faça [...] o que está principalmente em questão é quem eu sou e quem me tornarei, como serei com os outros", e acrescento, como podemos agir de modo que nos tornemos mais felizes, livres, realizados.

A hermenêutica filosófica "precisa ser compreendida como uma prática e que é uma prática que, devidamente compreendida, nos modifica. Essa modificação, essa transformação, vem para moldar nosso caráter. Ela afeta e forja o que entendemos pela palavra do grego antigo ethos" (Schmidt, 2014, p. 169). A instituição, pois, de uma vida feliz, livre e responsável passa pelo exercício de saber lidar com os direitos e as razões dos outros. Esse exercício, com feição dialógica, efetiva a instituição de um ethos mais harmônico, visto que seus parceiros “já não são exatamente os mesmos quando se separam”, mas, ao final "estão mais próximos um do outro" (Gadamer, 2001, pp. 232-233).

3.2. Construção de um mundo habitável, de um sentir-se em casa no mundo

A virtude de levar a sério e lidar com o direito e as razões do outro contribui para uma orientação teórica e prática que nos faculta a construção de um mundo habitável, de um espaço comum ou ethos no qual nos sentimos em casa, mais livres e realizados. O exercício de reconhecer os direitos e as palavras do outro no processo filosófico, possui implicações socioambientais, de acordo com Gadamer (in Risser, 1997, p. 20), para quem

\footnotetext{
talvez podemos sobreviver como humanidade se pudermos aprender que não podemos simplesmente explorar nossos meios de poder e possibilidades efetivas, mas devemos aprender a parar e respeitar o outro como um outro, seja a natureza ou as culturas das pessoas e nações; e se pudermos aprender a experimentar o outro e os outros, como o outro do nosso eu a fim de participar com outro.
}

Levar a sério a palavra do outro significa romper com a estrutura monológica da ciência moderna que rege os padrões da conduta humana cujas implicações sociais e ecológicas são nefastas. E isso se deve, em grande parte, ao fato de que, "apesar de todos os nossos progressos técnicos e científicos, não aprendemos suficientemente como se aprende a conviver, tanto com eles como com os próprios homens" (Gadamer, 2000, p. 26). O jogo dialógico que articula os direitos e as razões do outro, proposto pela hermenêutica, faculta a compreensão do mundo enquanto um todo, cuja prática se orienta pelo padrão da troca de passes, da construção de elos, de redes, de jogadas conjuntas. Penso que esse modelo de jogo contribui para a construção de um mundo habitável, solidário, em que nos sentimos em casa, em que não reina a violência nem a destruição da natureza (Gadamer, 2001, p. 234). 
A construção de um mundo no qual possamos nos sentir em casa assentase sobre o exercício da responsabilidade mútua, que se estampa na virtude da solidariedade que subjaz à teoria e prática da hermenêutica:

na solidariedade que se declara, seja livremente ou à força, há sempre, em qualquer caso, uma renúncia aos interesses e preferências mais próprios. A solidariedade nos faz renunciar a certas coisas em uma certa direção, em um certo momento, a serviço de um certo objetivo (Gadamer, 2002, p. 86).

Levar a sério o direito e o argumento do outro implica uma prática solidária, enquanto um jogo de fusão de horizontes segundo o pressuposto de que somos seres linguísticos que visamos, desde os primórdios da humanidade, de uma ou de outra forma, instituir um ethos de parceria, de harmonia e de cooperação mútua. Jogar com a possibilidade do outro ter razão em suas jogadas, pressupõe autocontrole e parceria por parte de quem se dispõe a jogar. O jogador que pretende determinar o movimento total do jogo não atua solidariamente e, efetivamente, não joga e, assim, não contribui para sentir-se em casa no mundo.

A instituição de um ethos mais harmônico passa pelo exercício de integrar, no discurso e na prática, os direitos e os argumentos dos outros. Se Creonte tivesse feito isso teria, talvez, evitado a tragédia familiar que perpetrou. Diante do dogmatismo, dos radicalismos em suas diferentes versões, penso que a melhor alternativa que temos é de cultivar a forma de pensar segundo o todo ou ecumênica, uma virtude própria da hermenêutica, a saber, a de reconhecer que se trata

em primeiro lugar, de compreender o outro, a fim de ver se, quem sabe, não será possível, afinal, algo assim como solidariedade da humanidade enquanto um todo, também, no que diz respeito a um viver junto e a um sobreviver com o outro, então - se isso não acontecer - não poderemos realizar as tarefas essenciais da humanidade, nem no que tem de menor nem no que tem de maior (Gadamer, 2000, p. 25).

\section{Algumas conclusões}

Enfim, se por um lado, a hermenêutica filosófica estriba-se sobre a assunção e o exercício do pressuposto segundo o qual precisamos tratar o outro como fim em si mesmo, no sentido de que é portador de direitos que precisam ser assegurados, por outro lado, a instituição de uma linguagem comum e crítica passa pela arte de lidar com a possibilidade de que o outro pode, também, ter razão. Procurei sustentar que esses pressupostos e suas práticas participam do labor filosófico porque nos possibilitam instituir conceitos universais, nos 
instigam a analisar nossos argumentos mediante exercício judicativo, nos lembram do compromisso e da responsabilidade que temos ao compreendermos o outro - pessoas, fatos, obras etc.

No bojo da hermenêutica filosófica, não encontramos a defesa de uma relação de dependência do outro em relação ao eu nem sua absolutização. Embora se tenha atribuído a Gadamer a primazia do outro em detrimento do eu, ou da história relativa à subjetividade, respaldável por sua afirmação de "que não é a história que nos pertence, mas nós a ela", a relação que propõe entre o eu e o outro é de uma dialética em aberto. Isso se visualiza pela prática do jogo onde a relação entre ambos é salutar e sempre tensional, dialética; no caso, entre direitos e argumentos dos jogadores. Não se justifica a absolutização do outro que desembocaria na submissão do eu (Heleno, 2001, p. 403). A relação proposta a partir da assunção dos pressupostos em questão não é de fundição nem de anulação do eu em relação ao outro, como poderia ser justificado pela noção de fusão de horizontes. A fusão de horizontes não pressupõe nem implica fundição do eu no outro numa unidade indiferenciada. A fusão de argumentos, de visões e vivências, não implica a eliminação da posição do eu nem do outro, mas na ampliação da visão de ambos e numa práxis pautada pela liberdade.

Levar a sério e saber lidar com a possibilidade de que o outro possa ter razão nos põe a tarefa de aprendermos a reconhecer os direitos e de nos abrirmos aos argumentos e às palavras dos outros. É nessa articulação dialética que será possível instituir um ethos hermenêutico, isto é, um "espaço dialógico entre o eu e o outro e assim para além do dogma e da doxa" (Kögler, 2014, p. 15). A originalidade da reflexão aqui consistiu em evidenciar a centralidade do outro na teoria e na prática hermenêutica filosófica o que a justifica como uma proposta ética uma vez que articula os direitos e as razões do outro em relação ao eu hermeneuticus. Essa perspectiva, como mostrei, é imprescindível para criarmos um ethos onde reina a liberdade, a criatividade e a possibilidade, inclusive, de evitarmos a destruição do nosso planeta. Dito de outra forma, a proposta ética calcada na centralidade do outro com seu direito aos seus direitos e ao exercício da argumentação, como mostrei, se contrapõe-se às teorias e às práticas xenofóbicas, homofóbicas, racistas.

Procurei mostrar que, ao aprendermos a levar a sério o outro, poderemos construir um ethos suportável, harmônico, agradável que nos possibilitará evitar a destruição planetária. Justifiquei que, se não aprendermos a reconhecer o direito e conceder, talvez, também, razão ao outro, não teremos condições de cessar a marcha da destruição da vida calcada na postura que ignora e destrói toda forma de alteridade. Nesse sentido, é imprescindível que aprendamos "a pensar de forma oikoumênica [...] É a humanidade sobre este globo que tem que 
fazê-lo para aprender a conviver e talvez poder adiar assim a autodestruição" (Gadamer, 2001, p. 223). Procurei justificar que a nossa realização e felicidade plenas se estribam no exercício de aprendermos não apenas a concedermos o direito ao direito do outro, mas a lidarmos com a possibilidade de que ele possa, talvez, também ter razão. A fundamentação ética desse pressuposto está corporificada nas palavras de Hemon quando advertiu seu pai Creonte a reconsiderar sua decisão acerca do direito do outro e concomitante necessidade de reconhecer, também, suas as razões:

não tenhas, pois, um sentimento só, nem penses que só tua palavra e mais nenhuma outra é certa, pois se um homem julga que só ele é ponderado e sem rival no pensamento e nas palavras, em seu íntimo é um fútil. Não há vergonha alguma, mesmo sendo sábio, em aprender cada vez mais, sem presunções (Sófocles, 1990, p. 226). ${ }^{3}$

Penso que boa parte das tragédias pessoais, sociais, políticas e ecológicas têm sua origem e seu fundamento na incapacidade ou no propósito de não querer saber lidar com o direito e com os argumentos dos outros. Sófocles captou e expressou isso magistralmente, em sua trilogia tebana, ao mesmo tempo que nos brindou, com seu texto, o antídoto apropriado para evitá-las ou, ao menos, minimizar seus efeitos. Creonte foi incapaz de se abrir, de se sensibilizar, de entrar no horizonte do outro, isto é, de se deixar tocar pelo direito e pelos argumentos da Antígona. Apesar das advertências do seu filho Hemon e do cego Tirésias, ele consumou a tragédia porque se recusou a ouvir, a se colocar no lugar do outro, a reconhecer o direito ao direito do outro, a lidar com o argumento do outro. A grande lição de Sófocles consistiu em evidenciar que a raiz de toda espécie de tragédia está relacionada com a incapacidade e a recusa de reconhecer o direito e os argumentos dos outros.

Como se vê, já em Sófocles encontramos desenvolvida a justificativa de que a instituição de um ethos habitável e, minimamente harmônico, passa, necessariamente, pela prática segundo o qual o outro também pode ter razão. Esse pressuposto representa, na verdade, uma contraposição ao reino da lógica

3 Gosto também das demais traduções dessa parte, que alargam o sentido da formulação em questão, a saber, de Donaldo Schüler, que traduziu assim: "não carregues em ti só uma morada da verdade: o que tu dizes, nada mais que isso. Quem julga deter saber exclusivo, possuir língua e mente estranhas aos demais, nesse, se o abres, verás o vazio. Para o homem, ainda que seja sábio, aprender continuamente e ser flexível não é vergonhoso" (Sófocles, 2017, p. 51); e esta outra, de J.B. de Mello e Souza: "mas não creias que só tuas decisões sejam acertadas e justas... Todos quantos pensam que só eles têm inteligência, e o dom da palavra, e um espírito superior, ah! esses, quando de perto os examinarmos, mostrar-se-ão inteiramente vazios! Por muito sábios que nos julguemos, não há desar em aprender ainda mais, e em não persistir em juízos errôneos" (Sófocles, 2005, p. 46). 
dogmática, da pura positividade, da coação, do totalitarismo e uma defesa do reino da possibilidade, da terceira margem, da poesia, da criatividade e, enfim, da liberdade.

\section{Referências}

GADAMER, H.G., KOSELLECK, R. "Hermeneutik und Historik". Heidelberg: Winter, 1987.

. "La incapacidad para el diálogo". In: . Verdad y Metodo II. Salamanca: Ediciones Sígueme, 1992, pp. 203-210. 1993a. . "Über die Verborgenheit der Gesundheit". Frankfurt a.M.: Suhrkamp Verlag, . "Wahrheit und Methode". Tübingen: Mohr Siebeck, 1993b. GW2. ."Wahrheit und Methode". Tübingen: Mohr Siebeck, 1999. GW1.

. "Da palavra ao conceito". In: ALMEIDA, C.L.S. de; FLICKINGER, H.G; ."Europe y la "oikoumene". In: . El Giro Hermenéutico. Madrid:

Ediciones Cátedra, 2001, pp. 219-238.

. "Amistad y solidariedad". In: . Acotaciones hermenéuticas. Madrid:

Editorial Trotta, 2002. pp. 77-90.

GEORGE, T. “Responsibility to Understand”. In: HEIDEN, G.J (ed.). Phenomenological Perspectives on Plurality. Leiden: Brill Publishing, 2014, pp. 103-120.

GRONDIN, J. "Einführung in die Philosophische Hermeneutik". Darmstadt: Wiss. Buges., 1991.

HELENO, J.M.M.H. “Hermenêutica e Ontologia em Paul Ricoeur”. Lisboa: Instituto Piaget, 2001.

KÖGLER, H-H. "The Crisis of a Hermeneutic Ethic". Philosophy Today, Vol. 58, Issue 1, pp. 9-22, 2014.

RISSER, J. "Hermeneutics and the voice of the Other: re-reading Gadamer's Philosophical Hermeneutics". New York: State University of New York Press, 1997.

ROHDEN, L. "Hermenêutica filosófica: uma configuração entre a amizade aristotélica e a dialética dialógica". Sintese (Belo Horizonte), Vol. 31, pp. 191-212, 2004.

. "Hans-Georg Gadamer: educação em direitos humanos". In: MÜHL, E.H.

(ed.). Textos referenciais para Educação em Diretos Humanos. 2a. ed. Passo Fundo: Ed. IFIBE, 2013. Vol. 1, pp. 138-142.

. "Hermenêutica Filosófica". São Leopoldo: Ed. Unisinos, 2003.

ROHDEN, L. Hermenêutica Filosófica: nas trilhas de Hans-Georg Gadamer. Porto Alegre: Edipucrs, 2000, pp. 13-26.

SCHMIDT, D.J. "On the sources of ethical life". Research in Phenomenology, Vol. 42, pp. 35-48, 2012.

. "O Texto e o Jardim: A leitura do Fedro de Platão sobre a Leitura e a Tarefa Ética da Hermenêutica”. In: ROHDEN, L. (org.). Hermenêutica e Dialética: entre Gadamer e Platão. São Paulo: Loyola, 2014. pp. 169-184. 
SMITH, P. Christopher. "The Ethical dimension of Gadamer's Hermeneutical Theory". Research in Phenomenology, Vol. 18, pp. 75-91, 1988.

SÓFOCLES. “A trilogia tebana: Édipo Rei, Édipo em Colono, Antígona”. Trad. M. da Gama Cury. Rio de Janeiro: Jorge Zahar Editor, 1990.

. "Antígone". Trad. J. B. de Mello e Souza. Versão para eBook. [S.1.], 2005.

. "Antígona". Trad. D. Schüler. Porto Alegre: L\&PM, 2017.

STRECK, L. L. "Hermenêutica Jurídica e(m) Crise: uma exploração hermenêutica da construção do Direito". 11a. ed. Porto Alegre: Livraria do Advogado, 2013. . "Verdade e Consenso". 6a. ed. São Paulo: Saraiva, 2017. 